\title{
OBSERVATION OF CHILDREN AT A PUPPET THEATER PERFORMANCE
}

\section{Grace Johnson}

A number of Kirkwood Community College employees and their children viewed a performance by the Eulenspiegel Puppet Theater. The story presented via the puppets is a Finnish folk tale of an allegorical nature, complete with a "moral-of-the-story" conclusion. Thus, the story line, as represented through the dialogue and actions of the puppets, incorporates both humorous and dramatic elements. The puppets assumed human qualities in appearance, speech and expression and were life-like in their portrayal of the story characters. Although manipulated by the artists, the puppets seemed to develop independent personalities and characteristics.

In one episode a human artist portrayed a story character by assuming a role and carrying it out through appropriate costume, dialogue, and voice intonation. On occasion the puppets were physically taken into the audience to interact individually with observers. On these occasions children were asked to participate through conversation with the puppets. The effort to have the puppets appear life-like was quite successful and this was evidenced by the audience participation.

Observation of the activity:

Reaction to the puppets by the children ranged from laughter and curiosity to embarassment and fear. The puppets were accepted, however, as being "real" even by children mature enough to realize that they were lifeless objects manipulated by humans. They all were willing to accept "fantasy" as "reality" for the duration of the performance. The puppets, in appearance 


\section{Grace Johnson}

and character, were caricatures of personality types, and easily recognizable in the children's own experiences and were accepted as such.

Theme of the Experience:

Children, as observers and participants in an "art experience" are willing-and eager--to accept fantasy as reality and to allow themselves free expression of emotions in reaction to the stimuli presented.

Evidence to Support Theme:

The accompanying photographs (the photographs are not reproduced in this publication) provide visual, recorded evidence of the wide range of emotions displayed by the children as they participated in this puppet "experience." The facial expressions especially indicate the intensity of their belief in the characters and in the reality of the story being presented. The photographs also suggest a willingness, even eagerness, on the part of the children to be entertained and informed--and to interact with the puppets. Frequently, the children became totally drawn into the experience and displayed obvious concern or delight with the entire situation.

Conclusion:

The results of this observation are multi-dimensional. Several factors were interacting to produce a rich learning experience for the children in the audience. A researcher could choose to select evidence/data for a variety of themes, al1 present in this experience and available through observation:

Puppetry as art 


\section{Grace Johnson}

Puppet theater as a form of socialization

Audience participation in "Theater"

Willingness to accept premise presented by performers

Interaction of audience with characters/performers

Allegorical folk tales--effect upon a mixed-aged audience

Difference in reactions of adults and children in an art experience

The value of art as entertainment/education

In reflecting upon this experience, it is difficult for a researcher to verbally describe the emotive response and sense of "theater" present during this performance. It is equally difficult to separate the reactions of audience participants toward the artistic value of the puppets themselves (as works of art), puppetry as performing art, and the literary art of the story being presented. These elements were so finely integrated that to isolate the effect of any single factor would be impossible without contaminating the data by observer bias. It appeared that, in this situation, the overriding commonality was the expressiveness of the population being observed (children in the audience) and their reactions to the puppetry experience. 